\title{
Improved asthma control with budesonide/formoterol in a single inhaler, compared with budesonide alone
}

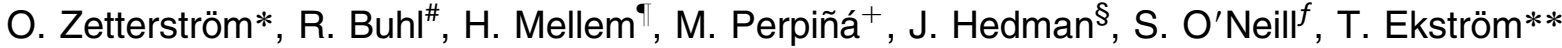

Improved asthma control with budesonidelformoterol in a single inhaler, compared with budesonide alone. O. Zetterström, R. Buhl, H. Mellem, M. Perpiñá, J. Hedman, S. O'Neill, T. Ekström. (C)ERS Journals Ltd 2001.

ABSTRACT: Budesonide/formoterol in a single inhaler was compared with budesonide alone, and with concurrent administration of budesonide and formoterol from separate inhalers, in patients with asthma, not controlled with inhaled glucocorticosteroids alone.

In this 12-week, double-blind, randomized, double-dummy study, 362 adult asthmatics (forced expiratory volume in one second $73.8 \%$ of predicted, inhaled glucocorticosteroid dose $960 \mu \mathrm{g} \cdot \mathrm{day}^{-1}$ ) received single inhaler budesonide/formoterol

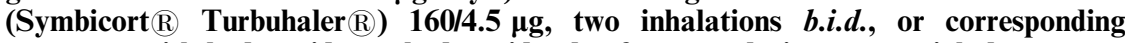
treatment with budesonide, or budesonide plus formoterol via separate inhalers.

There was a greater increase in morning peak expiratory flow (PEF) with singleinhaler $\left(35.7 \mathrm{~L} \cdot \mathrm{min}^{-1}\right)$ and separate-inhaler $\left(32.0 \mathrm{~L} \cdot \mathrm{min}^{-1}\right)$ budesonide and formoterol, compared with budesonide alone $\left(0.2 \mathrm{~L} \cdot \mathrm{min}^{-1} ; \mathrm{p}<0.001\right.$, both comparisons); the effect was apparent after 1 day ( $<<0.001$ versus budesonide, both comparisons). Similarly, evening PEF, use of rescue medication, total asthma symptom scores and percentage of symptom-free days improved more with both single inhaler and separate inhaler therapy than with budesonide alone, as did asthma control days $(\sim 15 \%$ more, $p<0.001$ versus budesonide, both comparisons, with a marked increase in the first week). All treatments were well tolerated and the adverse event profile was similar in all three treatment groups.

It is concluded that single inhaler therapy with budesonide and formoterol is a clinically effective and well-tolerated treatment for patients with asthma that is not fully controlled by inhaled glucocorticosteroids alone.

Eur Respir J 2001; 18: 262-268.
*Karolinska Hospital, Stockholm, Sweden, "Mainz University Hospital, Germany, Ullevål Hospital, Oslo, Norway, ${ }^{+} \mathrm{La} \mathrm{Fe}$ University Hospital, Valencia, Spain, ${ }^{\$}$ Päijät-Häme Central Hospital, Lahti, Finland, Beaumont Hospital, Dublin, Ireland and A*AstraZeneca, Lund, Sweden.

Correspondence: O. Zetterström, Karolinska Sjukhuset, Allergicentrum Universitetssjukhuset, S-581 85 Linköping, Sweden.

Keywords: Asthma

budesonide

formoterol

glucocorticosteroids

inhalation

Received: July 212000

Accepted after revision March 282001

This study was supported by AstraZeneca, Lund, Sweden.
Effective control of asthma symptoms and maintenance of optimal lung function are critical for the long-term management of patients with persistent asthma. The use of inhaled glucocorticosteroids as first-line treatment for the management of patients with all but intermittent asthma is firmly established [1-3]. However, many patients taking inhaled glucocorticosteroids still suffer from asthma symptoms and exacerbations necessitating use of relief medication with short-acting $\beta_{2}$-agonists. Increasing use of shortacting $\beta_{2}$-agonists is often associated with poor asthma control. Moreover, the regular use of shortacting $\beta_{2}$-agonists has been questioned [4].

In patients receiving inhaled glucocorticosteroids whose asthma is not fully controlled, national and international guidelines recommend a step-wise approach [1-3]. Increasing the dose of inhaled glucocorticosteroid or, alternatively, the addition of a long-acting $\beta_{2}$-agonist to low-dose inhaled glucocorticosteroids are two therapeutic options. Recent evidence suggests that the addition of a long-acting $\beta_{2}$-agonist to inhaled glucocorticosteroids may be more beneficial in terms of asthma control than increasing the dose of corticosteroids alone [5-7]. The long-term use of long-acting $\beta_{2}$-agonists has been challenged with respect to their potential to mask the progression of airway inflammation and thereby worsen asthma [8].

In the recent long-term study by PAUweLs et al. [9], the addition of the long-acting $\beta_{2}$-agonist formoterol to budesonide (high or low dose) for $1 \mathrm{yr}$ improved asthma symptoms and lung function without any deterioration in asthma control [9]. Formoterol decreased the incidence of both mild and severe asthma exacerbations independent of the dose of budesonide. However, a higher dose of budesonide plus formoterol resulted in the greatest reduction in the rate of severe exacerbations [9]. A second 1-yr study, by KIPS et al. [10], showed that adding formoterol to low-dose budesonide treatment in patients with moderate asthma did not lead to a significant increase in sputum markers of airway inflammation compared with a four-fold higher dose of budesonide treatment alone. From these studies, it is apparent that the addition of formoterol to budesonide in patients whose asthma is not fully controlled, offers the potential to optimize control of asthma.

This study is the first to report the efficacy and safety of the new single Turbuhaler $(\mathbb{R}$ inhaler therapy, Symbicort $\mathbb{R}$. The single inhaler containing 
budesonide and formoterol, and the concurrent administration of budesonide and formoterol in two separate inhalers, were compared with budesonide alone in patients with symptomatic asthma despite previous regular treatment with inhaled glucocorticosteroids.

\section{Methods}

\section{Patients}

Male and female asthma patients aged $\geqslant 18$ yrs were eligible for inclusion in the study if: 1) they were using inhaled glucocorticosteroids at a constant daily dose of $\geqslant 500 \mu \mathrm{g}$ for $\geqslant 30$ days before entry; 2) they had a baseline forced expiratory volume in one second (FEV1) of 50-90\% predicted; and 3) they had a reversibility from baseline of $\geqslant 15 \%$ after inhalation of terbutaline sulphate $1 \mathrm{mg}$ (Bricanyl®) Turbuhaler $(\mathrm{R})$ or salbutamol $0.4 \mathrm{mg}$.

Exclusion criteria included: use of oral, parenteral or rectal glucocorticosteroids within 30 days before study entry; respiratory infection; seasonal asthma; severe cardiovascular disorder; beta-blocker therapy; a history of heavy smoking ( $\geqslant 10$ pack-yrs); pregnancy or failure to use acceptable contraceptives in women of childbearing potential.

The present study was conducted in accordance with the Declaration of Helsinki. The local ethics committees approved the study protocol and all patients gave written informed consent prior to study commencement.

\section{Study design}

This was a randomized, double-blind, doubledummy, active-controlled study with a parallelgroup design conducted at 59 centres in Finland, Germany, Ireland, Norway, Spain and Sweden. At an initial visit (visit 1), patients underwent a physical examination and complete medical and respiratory histories were taken. This and subsequent visits (visits 2-5) took place between 07.00 and $10.00 \mathrm{~h}$.

Computerized randomization occurred on a percountry basis and individual treatment codes were kept in sealed envelopes until data analysis. To ensure treatment blinding, the patients successively used three numbered inhalers (identical in appearance to the corresponding placebo) each morning and evening.

After a 2-week run-in period, during which the patients continued with their usual inhaled glucocorticosteroid therapy, patients were allocated to randomized treatment (two inhalations b.i.d.) for 12 weeks with the following: single inhaler therapy containing budesonide $(160 \mu \mathrm{g})$ and formoterol $(4.5 \mu \mathrm{g})$ (budesonide/formoterol; Symbicort $\AA$ 160/4.5; AstraZeneca, Lund, Sweden); budesonide $(200 \mu \mathrm{g})$ plus formoterol $(4.5 \mu \mathrm{g})$ via separate inhalers; or budesonide $(200 \mu \mathrm{g})$ alone. The new Turbuhaler $\mathbb{R}$ (single inhaler therapy) has a dose counter, an externally tapered mouthpiece, and measures dose as delivered dose. The original Turbuhaler $\mathbb{R}$ (budesonide alone) measured metered dose; hence the doses of budesonide in each treatment group were equivalent, as were the doses of formoterol.

No concomitant asthma medication, except rescue medication with terbutaline sulphate (Bricanyl $\mathbb{R}$ ) Turbuhaler $\AA$ ) or salbutamol, was allowed during the study. The need for oral corticosteroids led to withdrawal of the patient from the study. Inhalation technique of the patients was assessed at each clinic visit.

\section{Efficacy assessments}

Peak expiratory flow (PEF) measurements and severity of asthma symptoms were recorded each morning and evening by the patients on diary cards for the duration of the study. Baseline diary data for $\geqslant 7$ of the last 10 days of run-in were required at randomization. PEF was measured using a mini-

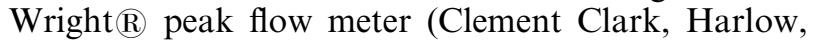
UK) before intake of study medication, and the highest of three values was recorded. Daytime and night-time asthma symptoms were each graded on a scale of $0-3(0=$ none; $1=$ mild; $2=$ moderate; $3=$ severe). Total asthma symptom score (on a scale of 0-6) was the sum of daytime and night-time symptoms scores. Symptom-free days were defined as days with a total asthma symptom score of 0 and no night-time awakening. Night-time awakenings due to asthma symptoms and use of rescue medication were also recorded. Asthma control days (from patients' diaries) were defined as days with no nocturnal awakenings, no asthma symptoms and no rescue medication use. Adherence to therapy was assessed by reviewing patient diary cards.

Subjects made five visits during treatment: an initial visit (visit 1), a second randomization visit (visit 2) and three visits at 4-weekly intervals (visits 3-5). Assessments of lung function as per the European Respiratory Society Recommendations [11] were performed at all visits. The highest values of $\geqslant 3$ FEV1 and forced vital capacity (FVC) readings were recorded. A reversibility test was performed at visit 1 by measuring FEV1 before and after inhalation of terbutaline sulphate $1 \mathrm{mg}$ or salbutamol $0.4 \mathrm{mg}$.

The number of severe and mild exacerbations during the 12-week period was also assessed. Severe exacerbations were defined as the need for oral steroids, discontinuation due to worsening of asthma, or PEF $<70 \%$ of run-in mean on two consecutive days. Mild exacerbations were defined as two consecutive days with either: PEF $<80 \%$ of the run-in mean, a 24 -h period with $\geqslant 4$ inhalations of reliever medication above the mean run-in use, night-time awakening due to asthma or any combination of the above.

\section{Clinical safety assessments}

Adverse events were recorded at visits $2-5$, both spontaneously reported and in response to a standard question asked by the investigator. Laboratory 
assessments of clinical chemistry, haematology and urinalysis were conducted at the start and the end of the treatment period.

\section{Statistical analysis}

The primary efficacy variable was change in average morning PEF from baseline to study end. The primary objective was to compare the efficacy of the single inhaler (budesonide/formoterol) with that of budesonide alone. It was estimated that $100 \mathrm{sub}-$ jects would be needed to detect a $20 \mathrm{~L} \cdot \mathrm{min}^{-1}$ difference between the treatments (budesonide/formoterol in a single inhaler versus budesonide alone) with a power of $80 \%$ at the $5 \%$ significance level, assuming a residual standard deviation of $50 \mathrm{~L} \cdot \mathrm{min}^{-1}$. An active control group was also included for safety and to compare the efficacy of budesonide plus formoterol administered via separate inhalers with that of budesonide alone. The study was not designed to detect differences between both single inhaler and separate inhaler budesonide and formoterol groups.

All efficacy variables were analysed on an intentionto-treat basis, using data from all patients who had taken $\geqslant 1$ dose of study medication. For PEF measurements and other diary card variables, baseline was defined as the average over the last 10 days of run-in and treatment as the average over the entire treatment period. Changes from baseline were analysed by analysis of variance (ANOVA), with treatment and country as factors and the baseline value of the dependent variable as covariate. The spirometry variables measurements obtained at randomization (visit 2) were considered baseline values and baseline versus treatment results (last visit) were analysed in a multiplicative model, i.e. the logarithms of the values were subjected to an ANOVA similar to the one for diary-card variables, in order to allow comparison of percentage change rather than absolute change.

The time to first exacerbation was compared between groups using a log-rank test and further described as relative risk of an exacerbation using a Cox regression model with treatment as factor.

\section{Results}

A total of 405 patients were enrolled in the study and 362 of these patients (185 males, 177 females) were allocated to randomized treatment with single inhaler therapy $(n=123)$, separate inhaler therapy $(n=115)$ or budesonide alone $(n=124)$. All randomized patients were included in the efficacy and safety analyses. The three treatment groups were comparable with regard to baseline characteristics (table 1). The mean FEV1 was $73.8 \%$ pred, mean reversibility $22.5 \%$ and the mean dose of inhaled glucocorticosteroids $960 \mu \mathrm{g} \cdot \mathrm{day}^{-1}$. Self-reported adherence to study medication was high (mean $>98 \%$ ) in all three treatment groups.

The three treatment groups were comparable with respect to numbers and reasons for patients discontinuing treatment. A total of 53 patients (20 single inhaler therapy; 17 separate inhaler therapy; 16 budesonide alone) discontinued the study: 17 due to asthma deterioration (five single inhaler therapy; eight separate inhaler therapy; four budesonide); 19 due to other adverse events (eight single inhaler therapy; five separate inhaler therapy; six budesonide alone); and 17 due to other reasons (seven single-inhaler therapy; four separate-inhaler therapy; six budesonide alone).

\section{Efficacy}

Statistically significantly greater increases in morning and evening PEF were observed with single inhaler therapy $\left(35.7 \mathrm{~L} \cdot \mathrm{min}^{-1}\right.$ and $24.8 \mathrm{~L} \cdot \mathrm{min}^{-1}$, respectively) and separate inhaler therapy $\left(32.0 \mathrm{~L} \cdot \mathrm{min}^{-1}\right.$ and $22.3 \mathrm{~L} \cdot \mathrm{min}^{-1}$, respectively) than with budesonide alone $\left(0.2 \mathrm{~L} \cdot \mathrm{min}^{-1}\right.$ and $-3.7 \mathrm{~L} \cdot \mathrm{min}^{-1}$, respectively; $\mathrm{p}<0.0001$, both comparisons; table 2). The onset of effect with both single inhaler therapy and separate inhaler therapy on morning PEF was apparent from day 1 ( $p<0.0001$ versus budesonide, both comparisons). However, during the first 30 days of treatment single inhaler therapy tended to show a more rapid improvement in both morning and evening PEF, compared with separate inhaler therapy (fig. 1). This trend in favour of the single inhaler therapy versus separate inhaler therapy approached significance for morning PEF (primary variable) during weeks 2 and 3

Table 1. - Patient baseline characteristics

\begin{tabular}{|c|c|c|c|}
\hline Characteristics & Single inhaler therapy* & Separate inhaler therapy* & Budesonide \\
\hline Patients $n$ & 123 & 115 & 124 \\
\hline Mean age yrs (range) & $46.7(18-78)$ & $44.7(18-77)$ & $48.5(21-78)$ \\
\hline Male/female & $65 / 58$ & $58 / 57$ & $62 / 62$ \\
\hline Asthma duration yrs & 19.1 & 16.9 & 17.1 \\
\hline \multicolumn{4}{|l|}{ Smoking habits } \\
\hline Nonsmoker/current smoker/past smoker & $72 / 11 / 40$ & $69 / 13 / 33$ & 79/7/38 \\
\hline Mean pack-yrs & 5.5 & 5.0 & 5.2 \\
\hline Inhaled corticosteroid use $\mu \mathrm{g} \cdot \mathrm{day}^{-1}$ & 971 & 973 & 936 \\
\hline FEV1 \% pred & 73.6 & 74.7 & 73.1 \\
\hline Reversibility \% & 21.5 & 22.2 & 23.8 \\
\hline
\end{tabular}

FEV1: forced expiratory volume in one second. *: both groups received equivalent doses of budesonide and formoterol via single or separate inhalers. 
Table 2. - Mean change from baseline in efficacy variables: effect of 12 weeks' treatment with budesonide/formoterol single inhaler, budesonide plus formoterol separate inhalers and budesonide alone

\begin{tabular}{|c|c|c|c|}
\hline Efficacy variables & Single inhaler therapy & Separate inhaler therapy & Budesonide \\
\hline Patients $n$ & 123 & 115 & 124 \\
\hline \multicolumn{4}{|l|}{ Morning PEF $\mathrm{L} \cdot \mathrm{min}^{-1}$} \\
\hline Baseline value $\pm \mathrm{SD}$ & $359 \pm 116$ & $357 \pm 96$ & $359 \pm 107$ \\
\hline Change from baseline & $35.7 * * *$ & $32.0 * * *$ & 0.2 \\
\hline$(95 \% \mathrm{CI})$ & $(28.4-43.0)$ & $(24.5-39.4)$ & $(-7.1-7.6)$ \\
\hline \multicolumn{4}{|l|}{ Evening PEF $\mathrm{L} \cdot \mathrm{min}^{-1}$} \\
\hline Baseline value $\pm \mathrm{SD}$ & $376 \pm 118$ & $367 \pm 98$ & $373 \pm 108$ \\
\hline Change from baseline & $24.8^{* * *}$ & $22.3^{* * *}$ & -3.7 \\
\hline$(95 \% \mathrm{CI})$ & $(18.2-31.4)$ & $(15.5-29.0)$ & $(-10.3-3.0)$ \\
\hline \multicolumn{4}{|c|}{ Total asthma symptom score $(0-6)$} \\
\hline Baseline value $\pm \mathrm{SD}$ & $1.40 \pm 1.15$ & $1.27 \pm 1.03$ & $1.15 \pm 1.03$ \\
\hline Change from baseline & $-0.52 * * *$ & $-0.44 * *$ & -0.20 \\
\hline$(95 \% \mathrm{CI})$ & $(-0.65--0.39)$ & $(-0.57--0.31)$ & $(-0.33--0.07)$ \\
\hline \multicolumn{4}{|c|}{ Use of $\beta_{2}$-agonist (inhalations $\cdot$ day $^{-1}$ ) } \\
\hline Baseline value $\pm \mathrm{SD}$ & $2.2 \pm 2.3$ & $2.3 \pm 2.4$ & $2.2 \pm 2.4$ \\
\hline Change from baseline & $-0.99 * *$ & $-1.13 * * *$ & -0.44 \\
\hline$(95 \% \mathrm{CI})$ & $(-1.29--0.69)$ & $(-1.43--0.28)$ & $(-0.74-0.13)$ \\
\hline \multicolumn{4}{|l|}{ Reliever-use-free days \% } \\
\hline Baseline value $\pm \mathrm{SD}$ & $31.9 \pm 37.8$ & $30.5 \pm 39.4$ & $31.0 \pm 40.1$ \\
\hline Change from baseline & $31.9 * * *$ & $31.9 * * *$ & 12.8 \\
\hline$(95 \% \mathrm{CI})$ & $(26.3-37.5)$ & $(26.2-37.6)$ & $7.1-18.4$ \\
\hline \multicolumn{4}{|c|}{ Night-time awakenings due to asthma $\%$} \\
\hline Baseline value $\pm \mathrm{SD}$ & $15.8 \pm 25.1$ & $19.2 \pm 30.0$ & $15.6 \pm 27.5$ \\
\hline Change from baseline & -8.4 & -5.6 & -5.8 \\
\hline$(95 \% \mathrm{CI})$ & $(-11.4--5.4)$ & $(-8.7--2.5)$ & $(-8.8--2.7)$ \\
\hline \multicolumn{4}{|l|}{ Symptom-free days \% } \\
\hline Baseline value $\pm \mathrm{SD}$ & $26.2 \pm 36.9$ & $27.4 \pm 37.3$ & $31.9 \pm 40.0$ \\
\hline Change from baseline & $25.0 * * *$ & $22.3 * * *$ & 8.0 \\
\hline$(95 \% \mathrm{CI})$ & $(19.5-30.6)$ & $(16.6-28.0)$ & $(2.4-13.6)$ \\
\hline \multicolumn{4}{|l|}{ Asthma control days $\%$} \\
\hline Baseline value \pm SD & $21.3 \pm 34.0$ & $21.5 \pm 34.0$ & $24.1 \pm 36.6$ \\
\hline Change from baseline & $28.5^{* * *}$ & $26.9 * * *$ & 12.1 \\
\hline$(95 \% \mathrm{CI})$ & $(22.8-34.2)$ & $(21.1-32.8)$ & $(6.3-17.9)$ \\
\hline
\end{tabular}

PEF: peak expiratory flow; SD: standard deviation; CI: confidence interval. ${ }^{* *}: \mathrm{p}<0.01$ versus budesonide; $* * *: \mathrm{p}<0.01$ versus budesonide, no significant difference $(\mathrm{p}>0.05)$ was seen for the pair-wise comparisons between the single inhaler and separate inhaler groups.

$(\mathrm{p}<0.07$, post hoc analysis), with the size of the treatment difference ranging from $6-9 \mathrm{~L} \cdot \mathrm{min}^{-1}$ in each of the first 4 weeks.

Treatment with single inhaler therapy or separate inhaler therapy resulted in greater improvements than budesonide alone with respect to total asthma symptom scores, symptom-free days, days on which no rescue medication was used, and rescue medication usage measured by number of inhalations $\cdot$ day $^{-1}$ (table 2). Over the whole treatment period there was no statistically significant treatment difference between the single inhaler therapy group and those receiving separate inhaler therapy. Nevertheless, the change in total asthma symptom scores when plotted against time also showed that the reduction in asthma symptoms tended to be achieved more rapidly with single inhaler therapy compared with separate inhaler therapy (fig. 2).

Single inhaler therapy resulted in a significantly greater percentage of asthma control days compared with budesonide alone (table 2). Indeed, the benefits of both single inhaler therapy and separate inhaler therapy in this study were estimated to give patients $\sim 15 \%$ more asthma control days $(\mathrm{p}<0.001$ versus budesonide) and more than doubled the number of control days versus baseline (table 2). Moreover, during the first week of treatment, $14.2 \%$ and $12.3 \%$ improvements in asthma control days were obtained in the single inhaler and separate inhaler groups, respectively $(\mathrm{p}<0.001$ versus budesonide, both comparisons). This trend for a more rapid improvement in asthma control with the single inhaler versus separate inhaler therapy was also suggested by the KaplanMeier survival curves of the time to a first mild exacerbation in each study group (fig. 3). Overall, the Cox regression model estimated the risk of a mild exacerbation to be $38 \%$ lower in the single inhaler group and $35 \%$ lower in the separate inhaler group ( $\mathrm{p}=0.011$, versus budesonide). Severe asthma exacerbations occurred in eight $(6.5 \%), 11(9.6 \%)$ and $11(8.9 \%)$ patients in the single inhaler, separate inhaler and the budesonide groups, respectively. Too few severe exacerbations occurred during the study to detect differences between treatments.

There were increases in FEV1 and FVC from baseline in all treatment groups. After 12 weeks of therapy, the levels of FEV1 were greater with single inhaler therapy and separate inhaler therapy than with 

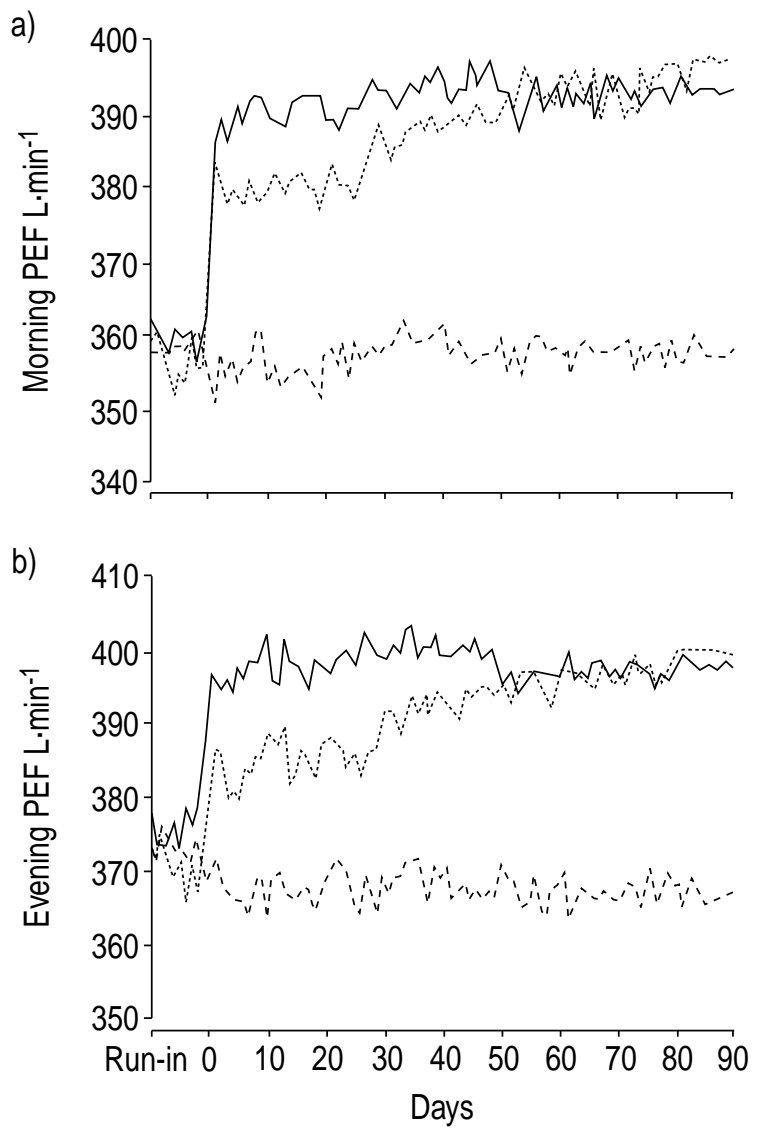

Fig. 1.-a) Morning and b) evening peak expiratory flow (PEF) (daily mean) during 12 weeks' treatment with budesonide/ formoterol (single inhaler therapy; - - , budesonide plus formoterol (separate inhaler therapy; $\cdots \cdots \cdots \cdots . . .$.$) or budesonide alone (-----).$

budesonide alone (table 3 ). There was no statistically significant difference between groups regarding the FVC.

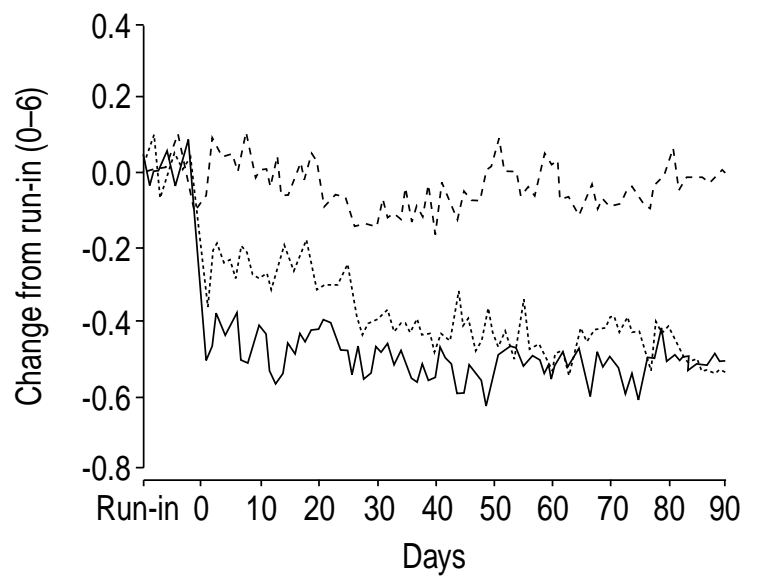

Fig. 2.-Change in total asthma symptom score (daily mean) during 12 weeks' treatment with budesonide/formoterol (single inhaler therapy; - - , budesonide plus formoterol (separate inhaler therapy; ….......), or budesonide alone (------).

\section{Clinical safety assessments}

The number, nature and intensity of adverse events were similar across the three treatment groups (table 4). Respiratory infection was the most commonly reported adverse event. There were five serious adverse events: four $(0.03 \%)$ in the single inhaler therapy group and one $(0.01 \%)$ in the budesonide alone group. None was considered to be related to treatment. The five serious adverse events were one death by suicide and four hospitalizations (due to pneumonia, liver cysts, ischaemic stroke and intervertebral disc prolapse).

No clinically important differences between treatments for any laboratory variable measured were observed.

\section{Discussion}

This study is the first to demonstrate that Symbicort $\AA$ (budesonide/formoterol administered via a single inhaler) is more effective than budesonide alone in patients whose asthma was not previously fully controlled by inhaled glucocorticosteroid treatment alone. This effect was evident in lung function, symptom scores and use of rescue medication. At the end of the study period, single inhaler treatment was also shown to be as effective and well tolerated as treatment with the monoproducts, budesonide plus formoterol, administered via separate inhalers. Furthermore, during the first 30 days of treatment, single inhaler therapy tended to show more rapid improvement in lung function and symptom scores compared with separate inhaler therapy. The improvement in lung function, reduction in symptom scores and reduction in rescue-medication usage attained in this 12-week study after administration of budesonide/ formoterol via a single inhaler, were similar to those achieved over a $1-y r$ period in the study by PAUwELS et al. [9] with separate inhalers.

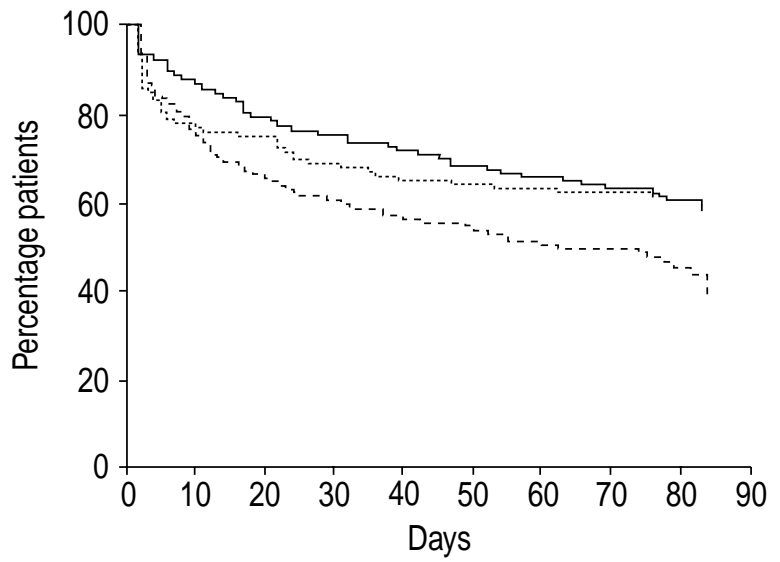

Fig. 3.-Probability of remaining exacerbation-free during 12 weeks' treatment with budesonide/formoterol single inhaler therapy (single inhaler therapy; - ), budesonide plus formoterol (separate inhaler therapy; ……..) or budesonide alone (-----) (Kaplan-Meier survival curves) 
Table 3. - Effect of 12 weeks' treatment with budesonide/ formoterol single inhaler, budesonide plus formoterol separate inhalers or budesonide alone on clinic assessed pulmonary function, expressed as geometric means (baseline data in table 1)

\begin{tabular}{|c|c|c|c|}
\hline $\begin{array}{l}\text { Efficacy } \\
\text { variables }\end{array}$ & $\begin{array}{l}\text { Single inhaler } \\
\text { therapy }\end{array}$ & $\begin{array}{l}\text { Separate } \\
\text { inhaler } \\
\text { therapy }\end{array}$ & Budesonide \\
\hline $\begin{array}{l}\text { Patients n } \\
\text { FEV1 L }\end{array}$ & 123 & 115 & 124 \\
\hline $\begin{array}{l}\text { Baseline } \\
\quad \text { value }(\mathrm{CV} \%)\end{array}$ & $2.28(39)$ & $2.33(35)$ & $2.24(36)$ \\
\hline $\begin{array}{l}\text { Week } 12 \\
(95 \% \mathrm{CI})\end{array}$ & $\begin{array}{c}2.47^{*} \\
(2.40-2.55)\end{array}$ & $\begin{array}{c}2.50 * * \\
(2.43-2.58)\end{array}$ & $\begin{array}{c}2.35 \\
(2.28-2.43)\end{array}$ \\
\hline $\begin{array}{l}\text { FVC L } \\
\text { Baseline }\end{array}$ & $3.30(38)$ & $3.36(31)$ & $3.24(33)$ \\
\hline $\begin{array}{l}\text { Week } 12 \\
(95 \% \text { CI })\end{array}$ & $\begin{array}{c}3.45 \\
(3.37-3.54)\end{array}$ & $\begin{array}{c}3.49 \\
(3.40-3.58)\end{array}$ & $\begin{array}{c}3.38 \\
(3.29-3.47)\end{array}$ \\
\hline
\end{tabular}

FEV1: forced expiratory volume in one second; CV: coefficient of variation; $\mathrm{CI}$ : confidence interval; FVC: forced vital capacity; *: $\mathrm{p}<0.05$ versus budesonide; **: $\mathrm{p}<0.01$ versus budesonide (for ratio of geometric means), no significant difference $(p>0.05)$ was seen for the pair-wise comparisons between the single inhaler and separate inhaler groups.

Although the patient population selected for enrolment in the study were treated with a mean inhaled steroid dose of $\sim 950 \mu \mathrm{g}$ daily and had a mean baseline FEV 1 of $73.8 \%$ of pred normal, baseline total asthma symptom scores were low and comparable between the three treatment groups. However, in spite of the low levels of symptoms reported, treatment with both single inhaler therapy and with budesonide plus formoterol in separate inhalers increased the percentage of asthma control days by $\sim 15 \%$ compared with budesonide alone. In effect, this implies that asthma patients treated with the single inhaler would have up to two additional months of asthma control per year.

Table 4.-Most frequently observed adverse events reported by the number of patients (\%) experiencing at least one adverse event during 12 weeks' treatment with budesonide/formoterol single inhaler, budesonide plus formoterol separate inhalers or budesonide alone

\begin{tabular}{lccc}
\hline Adverse event & $\begin{array}{c}\text { Single } \\
\text { inhaler } \\
\text { therapy }\end{array}$ & $\begin{array}{c}\text { Separate } \\
\text { inhaler } \\
\text { therapy }\end{array}$ & Budesonide \\
\hline Patients & 123 & 115 & 124 \\
Respiratory infection & $30(24.4)$ & $25(21.7)$ & $32(25.8)$ \\
Aggravated asthma & $7(5.7)$ & $9(7.8)$ & $5(4.0)$ \\
Viral infection & $6(4.9)$ & $7(6.1)$ & $5(4.0)$ \\
Pharyngitis & $6(4.9)$ & $4(3.5)$ & $6(4.8)$ \\
Rhinitis & $3(2.4)$ & $5(4.3)$ & $4(3.2)$ \\
Headache & $3(2.4)$ & $3(2.6)$ & $5(4.0)$ \\
Dysphonia & 0 & $4(3.5)$ & $5(4.0)$ \\
Coughing & $5(4.1)$ & $1(0.9)$ & $2(1.6)$ \\
Gastroenteritis & $1(0.8)$ & $2(1.7)$ & $5(4.0)$ \\
Back pain & $4(3.3)$ & $3(2.6)$ & $1(0.8)$ \\
\hline
\end{tabular}

The improved asthma control was also exemplified by a $38 \%$ reduction in the risk of a mild asthma exacerbation in the single inhaler group and a 35\% reduction in the separate inhaler group.

Asthma control in terms of managing exacerbations as well as treating the underlying pathophysiology of the disease, the inflammation, in the context of current treatment guidelines [1-3] is paramount. Success in gaining and maintaining control relies to a large extent on the patients or caregivers themselves in terms of participation in the management of their condition and adhering to the medication regimen. It has previously been reported that patient adherence to treatment decreases with increased complexity of treatment [12], including increased frequency of dosing and inhaler number [13, 14]. Although this double-blind, double-dummy study was not designed to investigate adherence to treatment, simplifying asthma treatment by providing a single inhaler containing both formoterol and budesonide should lead to better asthma control and is an outcome measure that should be investigated in future clinical trials.

The benefits of combining treatments are directly related to the properties of the monoproducts. Budesonide has been used effectively to control asthma in a wide range of patients, including children [15]. Formoterol has been shown to quickly gain control of asthma symptoms and then maintain that control over the course of a day or night [16]. Patients may feel an immediate effect; thus, it may be speculated that adherence to maintenance treatment with single inhaler therapy will be improved over treatment with separate inhalers. This means that it is unlikely that patients will use $\beta_{2}$-agonist treatment at the expense of glucocorticosteroids, which are crucial for inflammatory control. Furthermore, the use of inhaled budesonide together with formoterol may have some synergistic effects on efficacy $[9,17,18]$. In the present study, there was a tendency towards more rapid improvements in morning and evening PEF, and asthma symptom score with single inhaler therapy compared with separate inhaler therapy. The consistency of the effect of a more rapid improvement with the single inhaler versus separate inhalers was also reflected in the exacerbation profile (fig. 3). Consequently, a more rapid improvement in asthma control with the single inhaler versus separate inhalers and the possibility of a synergistic effect between budesonide and formoterol when administered via a single inhaler cannot be excluded, even though the differences between combination treatments in this study were small and not statistically significant. The present findings highlight the need for further studies in this area.

In summary, this study shows that budesonide/ formoterol single inhaler therapy gives better asthma control than budesonide alone, in patients not previously fully controlled by glucocorticosteroids alone. The full potential of this new, single inhaler therapy has yet to be explored. Future directions for research may include the possibility of synergy between budesonide and formoterol. 


\section{References}

1. Global Initiative for Asthma. Lenfant C, Khaltaev N, eds. Global strategy for asthma management and prevention. NHLBI/WHO Workshop Report (based on March 1993 meeting). Bethesda, Maryland, National Institutes of Health, National Heart, Lung and Blood Institute, 1995 (publication No. 96-3659).

2. British Thoracic Society. The British Guidelines on Asthma Management. 1995 Review and Position Statement. Thorax 1997; 52: Suppl. 1, S1-S20.

3. National Asthma Education and Prevention Program. Expert panel report II: guidelines for the diagnosis and management of asthma. Bethesda, Maryland, National Institutes of Health, 1997 (Publication No. 97-4051).

4. Spitzer WO, Suissa S, Ernst P, et al. The use of betaagonists and the risk of death and near death from asthma. N Engl J Med 1992; 326: 501-506.

5. Greening AP, Ind PW, Northfield M, Shaw G. Added salmeterol versus higher-dose corticosteroid in asthma patients with symptoms on existing inhaled corticosteroid. Lancet 1994; 344: 219-224.

6. Woolcock AJ. The combined use of inhaled salmeterol and inhaled corticosteroids. Eur Respir Rev 1995; 5: 142-145.

7. van der Molen T, Postma DS, Turner MO, et al. Effect of the long-acting beta agonist formoterol on asthma control in asthmatic patients using inhaled corticosteroids. Thorax 1997; 52: 535-539.

8. Lofdahl CG, Svedmyr N. Beta agonists - friend or foes? Eur Respir J 1991; 4: 1161-1165.

9. Pauwels RA, Löfdal CG, Postma DS, Tattersfild AE, $\mathrm{O}^{\prime}$ Byrne P, Ullman A. Effect of inhaled formoterol and budesonide on exacerbations of asthma. $N$ Engl J Med 1997; 337: 1405-1411.

10. Kips JC, $\mathrm{O}^{\prime}$ Connor BJ, Inman MD, Svensson K,
Pauwels RA, O'Bryne PM. A long-term study of the antiinflammatory effect of low-dose budesonide plus formoterol versus high-dose budesonide in asthma. Am J Respir Crit Care Med 2000; 161: 9961001.

11. Quanjer PH, Tammeling GJ, Cotes JE, Pedersen OF, Peslin R, Yernault JC. Lung volumes and forced ventilatory flows. Report of the Working Party on the Standardization of Lung Function Tests, European Community for Steel and Coal. Official Statement of the European Respiratory Society. Eur Respir J 1993; 16: Suppl., 5-40.

12. Eisen SA, Miller DK, Woodward RS, et al. The effect of prescribed daily dose frequency on patients' medication compliance. Arch Intern Med 1990; 150: 1881-1884.

13. Coutts JAP, Gibson NA, Paton JY. Measuring compliance with inhaled medication in asthma. Arch Dis Child 1992; 67: 332-333.

14. Horn CR, Clark TJH, Cochrane GM. Compliance with inhaled therapy and morbidity from asthma. Resp Med 1990; 84: 67-70.

15. Chapman K, Ringdal N, Backer V, Palmqvist M, Saarelainen S, Briggs M. Salmeterol and fluticasone propionate $(50 / 250 \mu \mathrm{g})$ administered via combination Diskus inhaler: as effective as when given via separate Diskus inhalers. Can Respir J 1999; 6: 45-51.

16. Barnes PJ, Pedersen S, Busse WW. Efficacy and safety of inhaled corticosteroids. New developments. Am J Respir Crit Care Med 1998; 157: S1-53.

17. Bartow RA, Brogden RN. Formoterol. An update of its pharmacological properties and therapeutic efficacy in the management of asthma. Drugs 1998; 55: 303322.

18. Adcock IM, Stevens DA, Barnes PJ. Interactions of glucocorticoids and beta 2 agonists. Eur Respir J 1996; 9: $160-168$. 